\title{
Artigo Original / Original Paper \\ Paspalum (Poaceae) das formações savânicas e campestres do Parque Ecológico Bernardo Sayão, Distrito Federal, Brasil
}

Paspalum (Poaceae) of savannas and grasslands from Bernardo Sayão Ecological Park, Federal District, Brazil

Ana Paula de Morais Lira Gouvêa ${ }^{1,2,4,5}$, José Francisco Montenegro Valls ${ }^{3} \&$ Regina Célia de Oliveira ${ }^{1}$

\begin{abstract}
Resumo
Apresenta-se um estudo taxônomico do gênero Paspalum (Poaceae) no Parque Ecológico Bernardo Sayão (PEBS). Paspalum possui mais de 350 espécies neotropicais, com centro de diversidade no Brasil Central. O PEBS está inserido na matriz urbana de Brasília, engloba nascentes e é coberto, principalmente, por cerrado sentido restrito e campo sujo, que são as fitofisionomias mais abrangentes do bioma Cerrado e as mais ameaçadas pela agricultura e pecuária, em decorrência da facilidade de mecanização. O estudo foi baseado em um ano de coletas quinzenais na área e ampla revisão de herbários. O gênero está representado no PEBS por 24 espécies, o que corresponde a $34 \%$ do total de espécies registradas no Distrito Federal. O presente artigo traz uma chave de identificação, descrições, comentários taxonômicos pertinentes ao reconhecimento dos táxons, época de coleta em floração, particularidades ambientais e ilustrações de alguns caracteres diagnósticos, auxiliando na identificação das espécies.
\end{abstract}

Palavras-chave: Cerrado, conservação, gramíneas, Panicoideae, taxonomia.

\begin{abstract}
A taxonomic study of the genus Paspalum (Poaceae) in the Bernardo Sayão Ecological Park (PEBS) is presented. Paspalum has more than 350 neotropical species, with the center of diversity in Central Brazil. The PEBS is part of the urban matrix of Brasília. It holds springs and is mainly covered by cerrado sentido restrito and campo sujo, which are the most extensive phytophysiognomies of the Cerrado biome and those most threatened by conversion to agriculture and livestock, due to the ease of mechanization. The study was based on a year of biweekly collections in the area and extensive herbarium review. The genus is represented in the PEBS by 24 species, which correspond to $34 \%$ of the total species of this genus registered in the Federal District. The present article presents a key for the identification, species descriptions, taxonomic comments pertinent to the recognition of the taxa, phenological data stressing the flowering periods, environmental peculiarities and illustrations of some diagnostic characters, helping in the identification of the species.
\end{abstract}

Key words: Cerrado, conservation, grasses, Panicoideae, taxonomy.

\section{Introdução}

Paspalum L. é um gênero predominantemente americano, com mais de 350 espécies (Sánchez-Ken 2010). É um dos quinze gêneros de Angiospermas mais ricos em espécies do Brasil (BFG 2018), que abriga a maior parte de sua diversidade, com a ocorrência confirmada de 216 espécies, 78 das quais endêmicas (Bonasora et al. 2015; Oliveira et al. 2015; BFG 2018; Reis et al. 2015; Scataglini et al. 2014).

A região brasileira do Centro-Oeste é detentora de alta diversidade florística. Dela têm sido descritas novas espécies, em anos recentes, como Paspalum rostratum D. Ramos, Valls \& R.C. Oliveira

\footnotetext{
${ }^{1}$ Universidade de Brasília, Inst. Ciências Biológicas, Prog. Pós-graduação em Botânica, CP 04457, 70910-970, Brasília, DF, Brasil.

${ }^{2}$ Instituto do Meio Ambiente e dos Recursos Hídricos do Distrito Federal - Brasília Ambiental (IBRAM), SEPN 511, bl. C, 70750-543, Brasília, DF, Brasil.

${ }^{3}$ Embrapa Recursos Genéticos e Biotecnologia, CP 02372, 70770-917, Brasília, DF, Brasil.

${ }^{4}$ ORCID: <https://orcid.org/0000-0002-4800-812X>

${ }^{5}$ Author for correspondence: florestaana@gmail.com
} 
(Ramos et al. 2011) e P. minutispiculatum P.A. Reis, R.C. Oliveira \& Valls (Reis et al. 2015), do Distrito Federal, P. cerradoense R.C. Oliveira \& Valls (Oliveira et al. 2015), de Goiás, e $P$. schesslii Bonasora \& G.H. Rua (Bonasora et al. 2015), do Mato Grosso. A literatura acima citada registra um total de 145 espécies de Paspalum nativas da Região Centro-Oeste, sendo 23 endêmicas.

O gênero ocorre em todas as regiões brasileiras, sendo muito frequente nas formações campestres e savânicas do bioma Cerrado. Além disto, muitas espécies de Paspalum do Centro-Oeste apresentam reconhecido valor econômico, por seu potencial forrageiro (Filgueiras \& Rodrigues 2016) e ornamental (Oliveira et al. 2016). Paspalum atratum Swallen, P. guenoarum Arechav., P. notatum Flüggé e $P$. oteroi Swallen são exemplos de espécies autóctones que já se destacam como forrageiras comercialmente cultivadas, por sua adaptação ao cultivo e produtividade (Filgueiras \& Rodrigues 2016).

Por sua importância ecológica e contribuição para a produção forrageira das formações naturais campestres do Novo Mundo, Paspalum tem sido objeto de numerosos estudos taxonômicos conduzidos por pesquisadores nacionais e internacionais, compilados por Zuloaga \& Morrone (2005). No entanto, esses trabalhos tendem a ser pouco acessíveis ao profissional sem envolvimento específico na taxonomia de gramíneas. Como o gênero engloba grande número de espécies, a identificação destas torna-se um processo difícil e demorado.

O Parque Ecológico Bernardo Sayão (PEBS) é um importante fragmento de Cerrado, com cerca de 200 ha, inserido na matriz urbana de Brasília e, portanto, com potencial de uso em iniciativas de educação ambiental. Preserva remanescentes de formações savânicas e campestres, sendo predominantemente coberto por cerrado sentido restrito e campo sujo, entretanto, também ocorrem, de forma isolada, manchas de campo limpo úmido, campo de murundu e vereda (Ribeiro \& Walter 2008), ambientes com grande ocorrência de gramíneas. O Parque protege as nascentes do córrego Rasgado, abarcando um pequeno trecho de mata de galeria.

Considerando que as áreas planas cobertas por cerrado sentido restrito têm sofrido intensa degradação, pela facilidade de mecanização agrícola e pelo rápido crescimento das cidades no Centro-Oeste, a existência do Parque contribui, significativamente, para a conservação de espécies típicas dessa fitofisionomia, incluindo as espécies nativas de Paspalum. Pelas especificidades e facilidade de acesso e circulação nesta Unidade de Conservação, espera-se que o PEBS seja um local de divulgação e pesquisa dos elementos autóctones da flora local.

Diante da importância de estudos regionais para ampliar o conhecimento da flora do Brasil e adicionar elementos para a compreensão da taxonomia de Paspalum no bioma Cerrado, o presente trabalho teve como objetivo realizar um levantamento das espécies de Paspalum das formações savânicas e campestres do Parque Ecológico Bernardo Sayão. São fornecidos chave analítica para a identificação dessas espécies, ilustrações de aspectos florais, dados ecológicos e de distribuição geográfica, além de comentários taxonômicos relativos a cada espécie.

\section{Materiais e Métodos}

O PEBS é uma Unidade de Conservação de Uso Sustentável, integrante do Sistema Distrital de Unidades de Conservação (Distrito Federal 2010). Está situado na região central do Distrito Federal (Fig. 1), entre as coordenadas $15^{\circ} 48^{\prime}-15^{\circ} 50^{\prime} \mathrm{S}$ e $47^{\circ} 47^{\prime}-47^{\circ} 49^{\prime} \mathrm{W}$.

Uma vez que a área não dispunha de um histórico de coletas sistemáticas, ou mesmo eventuais, de gramíneas, foram realizadas coletas aleatórias, quinzenais e restritas às espécies de Poaceae em período reprodutivo, para a elaboração da lista de espécies de ocorrência local. As coletas foram conduzidas de janeiro de 2016 a maio de 2017 e todas foram georreferenciadas. Houve um repasse em janeiro de 2018, realizado por J. Valls $\&$ M. Sousa. O material coletado foi herborizado seguindo as recomendações de Walter \& Cavalcanti (2005) e incorporado ao acervo dos herbários CEN, UB e HEPH, acrônimos de acordo com o Index Herbariorum (Thiers 2018).

As identificações dos táxons foram efetuadas com base em bibliografia especializada e por comparação com exemplares de herbário. A chave analítica e os termos utilizados nas descrições, foram baseados em Oliveira \& Valls (2001). É importante ressaltar que o gênero foi descrito com base no conjunto de espécies da área, assim como a descrição das espécies foi restrita às características dos exemplares coletados no local.

Para a verificação dos nomes científicos e autores de cada táxon, dados de distribuição de cada gênero e espécie no país, além do grau de ameaça das espécies, foi utilizado o tratamento de Paspalum em BFG (2018). 


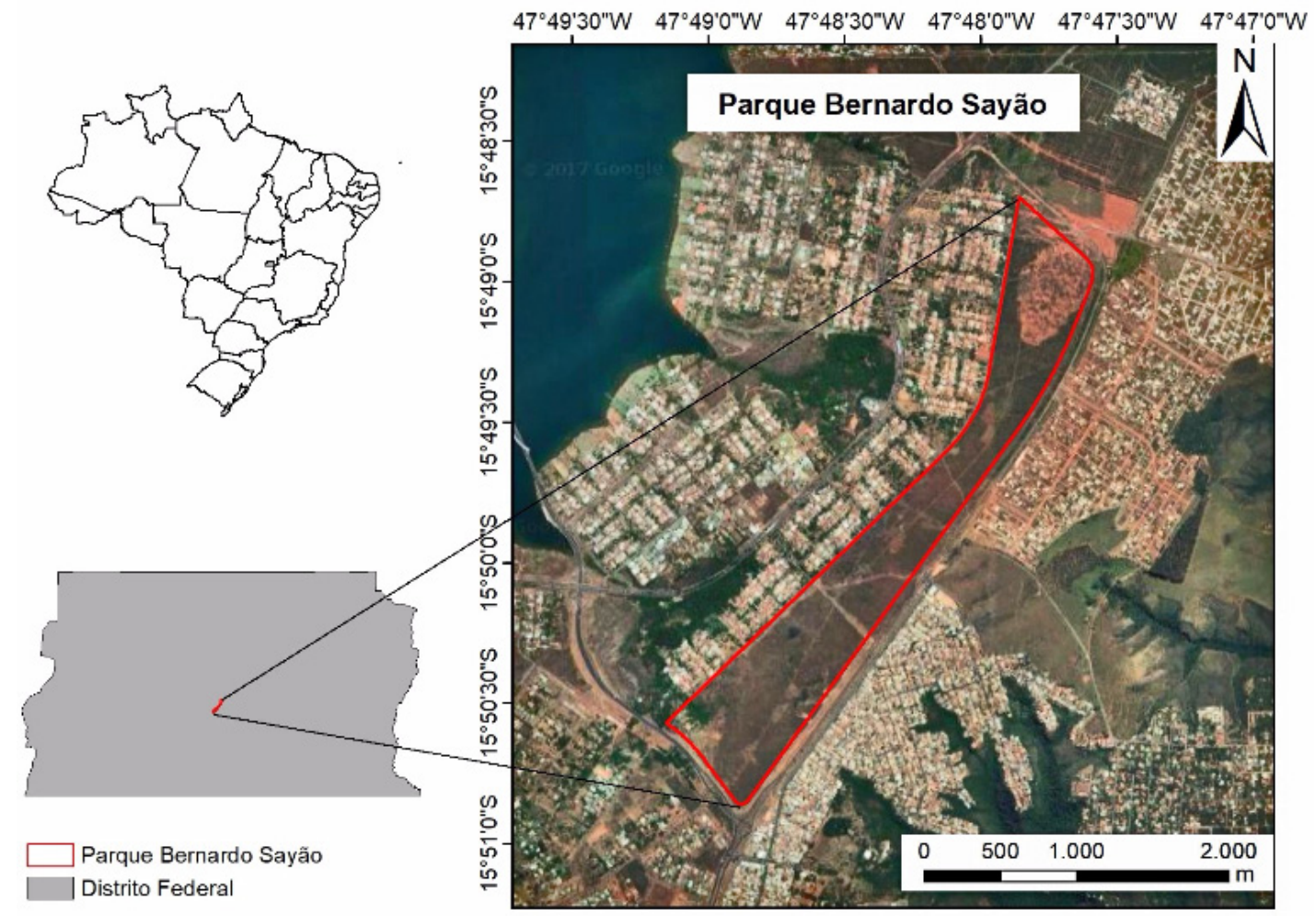

Figura 1 - mapa do Parque Ecológico Bernardo Sayão e sua localização no Distrito Federal, Brasil. Figure 1 - map of the Bernardo Sayão Ecological Park and its location in the Federal District, Brazil.

Os registros fotográficos a campo foram realizados com câmeras digitais. As espiguetas e estruturas menores foram fotografadas em câmera acoplada ao microscópio estereoscópio e pelo microscópio digital Dinolite AM 4113T. Os materiais selecionados para ilustração são aqueles considerados, pelos autores, bem representativos de cada espécie.

\section{Resultados e Discussão}

Tratamento taxonômico

\section{Paspalum L.}

Plantas anuais ou perenes, cespitosas, com ou sem rizomas ou estolhos. Lígulas membranosas. Lâminas foliares lanceoladas, lineares ou filiformes. Sinflorescência paniculada com 1-muitos ramos unilaterais espiciformes, alternos, conjugados ou solitários; ráquis áptera ou alada. Espiguetas acrótonas, plano-convexas, solitárias ou pareadas, múticas, glabras ou pilosas, elípticas a globosas; gluma inferior geralmente ausente, ou presente em algumas espécies $(P$. decumbens Sw., P. foliiforme S. Denham, P. geminiflorum Steud., P. pilosum Lam. e P. thrasyoides (Trin.) S.
Denham), muito mais curta que a espigueta; gluma superior raramente ausente (P. gardnerianum Nees e $P$. reduncum Nees ex Steud.), de comprimento subigual ao da espigueta; lema inferior áptero ou alado; pálea ausente, ou presente em algumas espécies (P. foliiforme, P. glaziovii (A.G. Burm.) S. Denham, $P$. pilosum e $P$. thrasyoides); lema superior adaxial à raquis, mútico, glabro ou com esparsos tricomas, não rugoso, papiloso a liso, sem apêndices, cicatrizes ou dilatações na base ventral; antécio superior cartáceo a coriáceo, estramíneo a castanho escuro na maturação.

Gênero predominantemente americano, com a maioria das espécies ocorrendo na América do Sul (Zuloaga \& Morrone 2005). Para o Brasil, foram compiladas 216 espécies, 78 das quais endêmicas, e 70 ocorrentes no Distrito Federal (Bonasora et al. 2015; Oliveira et al. 2015; BFG 2018; Reis et al. 2015; Scataglini et al. 2014). Paspalum minutispiculatum foi descrita posteriormente, como endêmica desta Unidade da Federação (Reis et al. 2015). O gênero é muito frequente no DF, ocorrendo em todas as suas Unidades de Conservação estudadas (Chacon et al. 2009; Felfili 
et al. 2007; Reis 2014; Ribeiro 2011; Rodriguesda-Silva \& Filgueiras 2003).

Sua ocorrência nas formações savânicas e campestres do PEBS é registrada por 24 espécies. Esse número de taxons é significativo, pois corresponde a cerca de $34 \%$ do total de espécies de Paspalum registrado no DF. As espécies localizadas no Parque são consideradas de ampla distribuição, exceto P. eucomum Nees ex Trin. e P. glaziovii, endêmicas do Cerrado. Não foram registradas espécies ameaçadas. As Figuras 2 a 6 ilustram as espécies de Paspalum discutidas neste trabalho.
As espécies encontradas em cerrado sentido restrito (cerrado ralo e cerrado típico) (Ribeiro \& Walter 2008) não diferiram, de forma geral, das espécies encontradas em campo sujo. Das 24 espécies, seis (25\%), estão restritas aos ambientes úmidos do PEBS, pouco representados em termos de área, o que sugere a alta diversidade do gênero em vereda e campo limpo.

Algumas espécies, como $P$. thrasyoides, $P$. pectinatum Nees ex Trin. e P. ammodes Trin. só foram encontradas florescendo após queimadas, que são frequentes na área.

\section{Chave de identificação das espécies do gênero Paspalum no PEBS}

1. Glumas ausentes.

2. Ráquis alada 3-3,2 mm larg.; pedicelos com tricomas mais curtos que o comprimento da espigueta

21. Paspalum reduncum

2'. Ráquis áptera 0,5-0,7 mm larg.; pedicelos com tricomas mais longos que o comprimento da espigueta

7. Paspalum gardnerianum

1'. Gluma superior presente.

3. Gluma superior com margens aladas.

4. Lema inferior alado, glabro

12. Paspalum imbricatum

4'. Lema inferior áptero, com tricomas tuberculados nas margens .... 17. Paspalum pectinatum

3'. Gluma superior com margens ápteras.

5. Sinflorescência composta por 2 ramos unilaterais espiciformes terminais conjugados ou subconjugados, às vezes com um terceiro ramo abaixo do par apical.

6. Espiguetas elípticas; lema inferior 5-nervado, nervuras conspícuas

13. Paspalum lineare

6'. Espiguetas orbiculares ou suborbiculares; lema inferior 3-nervado, apenas a nervura central conspícua.

7. Espiguetas douradas a castanho-escuras na maturação, com ou sem manchas irregularmente distribuídas

14. Paspalum maculosum

7'. Espiguetas estramíneas na maturação, sem manchas.

8. Planta anual. Espiguetas com tricomas glandulosos subglobosos

8. Planta perene. Espiguetas glabras

15. Paspalum multicaule 16. Paspalum notatum

5'. Sinflorescência composta por 1 ou 2 -muitos ramos espiciformes alternos (2 ramos subconjugados em $P$. guttatum e $P$. eucomum).

9. Antécio superior castanho escuro.

10. Gluma superior e lema inferior ornamentados por retículo de linhas irregulares de papilas translúcidas 8. Paspalum geminiflorum

10'. Gluma superior e lema inferior sem retículo de linhas irregulares de papilas translúcidas.

11. Espiguetas $2-2,5 \mathrm{~mm}$ compr.

19. Paspalum plicatulum

11'. Espiguetas 3-3,5 mm compr. 22. Paspalum rojasii

9'. Antécio superior esverdeado a estramíneo.

12. Espiguetas glabras.

13. Espiguetas solitárias; gluma inferior ausente; lema inferior com uma porção hialina no centro 11. Paspalum hyalinum

13'. Espiguetas pareadas; gluma inferior reduzida; lema inferior sem uma porção hialina no centro. 
14. Espiguetas elípticas; ráquis com tricomas tuberculados esparsos nas margens; gluma superior 5-nervada ..... 18. Paspalum pilosum

14'. Espiguetas obovadas; ráquis glabra a inconspicuamente escabrosa nas margens; gluma superior 3-nervada 3. Paspalum decumbens

12'. Espiguetas pilosas a pubescentes.

15. Gluma inferior ausente; pálea inferior ausente.

16. Espiguetas pareadas.

17. Ráquis áptera 0,5-0,7 mm larg., gluma superior 5-nervada .... 4. Paspalum erianthum 17'. Ráquis curto-alada 1-1,2 mm larg., gluma superior 3-nervada

20. Paspalum polyphyllum

16'. Espiguetas solitárias.

18. Pedicelos das espiguetas sem tricomas estrelados, antécio superior elíptico.

19. Ráquis áptera $0,2-0,3 \mathrm{~mm}$ larg.

1. Paspalum ammodes

19’. Ráquis alada $1-3 \mathrm{~mm}$ larg.

20. Lâminas foliares lineares, com estreitamento basal. Espiguetas 3-4,2 mm compr.

10. Paspalum guttatum

20'. Lâminas foliares filiformes, sem estreitamento basal. Espiguetas 4-4,5 mm compr.

2. Paspalum carinatum

18'. Pedicelos das espiguetas com tricomas estrelados, antécio superior obovado.

21. Lâminas foliares filiformes. Ráquis alada 1,5-3 mm larg.

5. Paspalum eucomum

21'. Lâminas foliares lanceoladas. Ráquis alada 6-8 $\mathrm{mm}$ larg.

23. Paspalum stellatum

15'. Gluma inferior presente, mas reduzida (ausente em P. glaziovii); pálea inferior presente.

22. Ráquis com margens glabras

6. Paspalum foliiforme

22'. Ráquis com margens pilosas.

23. Tricomas tuberculados dourados nas margens da ráquis, dorso glabro

24. Paspalum thrasyoides

23'. Tricomas não tuberculados alvos nas margens da ráquis, dorso piloso

9. Paspalum glaziovii

1. Paspalum ammodes Trin. $\quad$ Fig. 3g-h

Planta perene, cespitosa. Lâminas lineares, sem estreitamento basal. Sinflorescência com 1-5 ramos alternos, às vezes 2 conjugados no ápice do colmo florífero. Ráquis áptera $0,2-0,3 \mathrm{~mm}$ larg., inconspicuamente escabrosa nas margens; pedicelos inconspicuamente escabrosos. Espiguetas 2,8-3,2 mm compr., solitárias, pilosas; gluma inferior ausente; gluma superior áptera, 5-nervada, com tricomas tuberculados; lema inferior áptero, 5-nervado, com tricomas tuberculados, sem uma porção hialina no centro; pálea inferior ausente; antécio superior elíptico, estramíneo na maturação. Material examinado: Brasília, Parque Ecológico Bernardo Sayão, 27.X.2016, fl., A.P.M. Lira-Gouvêa et al. 171 (UB); 27.X.2016, fl., A.P.M. Lira-Gouvêa et al. 184 (UB).

Foi registrada em cerrado sentido restrito, campo limpo e áreas antropizadas. Coletada em floração em outubro. Sempre coletada fértil após queimadas. Espécie nativa com ampla distribuição, com registros de ocorrência em todas as regiões do país (BFG 2018).

Paspalum ammodes mostra afinidade com P. guttatum Trin. e P. erianthum Nees ex Trin. (Morrone et al. 2004), espécies que crescem frequentemente em áreas sujeitas a queimadas periódicas (Judziewicz 1990), e que apresentam bainhas persistentes e fibrosas na base das plantas, provavelmente relacionadas com a proteção de gemas (Morrone et al. 2004).

No PEBS, $P$. ammodes se diferencia por apresentar sinflorescências com 1-5 ramos unilaterais espiciformes alternos, enquanto $P$. guttatum mostra 2 ramos subconjugados (raramente um terceiro) e $P$. erianthum apresenta 3-12 ramos. Também possui lâminas foliares lineares, sem estreitamento basal, e espiguetas solitárias e menores (2,8-3,2 mm compr.), caracteres que a separam de $P$. erianthum, cujas lâminas foliares são lanceoladas com estreitamento basal e as espiguetas são pareadas e maiores (3,5-4 mm compr.). 

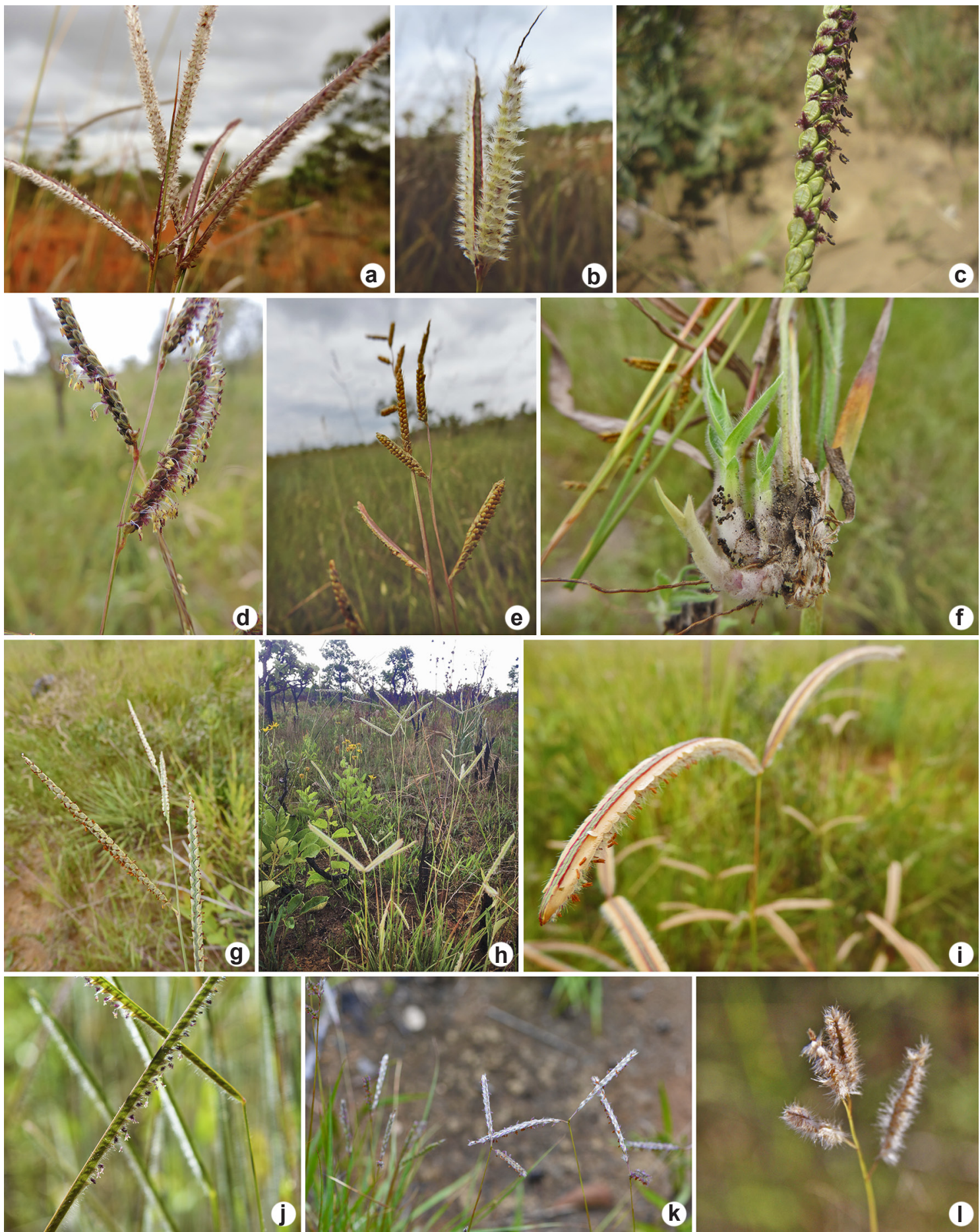

Figura 2 - Espécies de Paspalum do Parque Ecológico Bernardo Sayão-a-b. P. eucomum; c. P. rojasii; d. P. gardnerianum; e-f. P. reduncum; g. P. geminiflorum; h. P. pectinatum; i. P. stellatum; j. P. glaziovii; k. P. guttatum; 1. P. polyphyllum. Figure 2 - Species of Paspalum from PEBS - a-b. P. eucomum; c. P. rojasii; d. P. gardnerianum; e-f. P. reduncum; g. P. geminiflorum; h. P. pectinatum; i. P. stellatum; j. P. glaziovii; k. P. guttatum; 1. P. polyphyllum. 
2. Paspalum carinatum Humb. \& Bonpl. ex Flüggé

Fig. $5 \mathrm{~h}-\mathrm{i}$

Planta perene, cespitosa. Lâminas filiformes, sem estreitamento basal. Sinflorescência com 1 ou 2 ramos, quando 2, alternos. Ráquis $3 \mathrm{~mm}$ larg., margens glabras; pedicelos das espiguetas sem tricomas estrelados. Espiguetas 4-4,5 mm compr., solitárias, pilosas; gluma inferior ausente; gluma superior áptera, 3-nervada, densamente pilosa, sem tricomas tuberculados; lema inferior áptero, 3-nervado, piloso, sem uma porção hialina no centro; pálea inferior ausente; antécio superior elíptico, estramíneo na maturação.

Material examinado: Brasília, Parque Ecológico Bernardo Sayão, 18.I.2018, fl., J.F.M. Valls \& M.W.S. Sousa 16767 (CEN).

Foi registrada em campo sujo. Coletada em floração em janeiro. Ocorre em todas as regiões do Brasil (BFG 2018).

Paspalum carinatum pode ser confundida com $P$. guttatum Trin., da qual se distingue pelas lâminas foliares filiformes sem estreitamento basal, enquanto $P$. guttatum apresenta lâminas foliares lineares com estreitamento basal. Possui estrutura semelhante a uma bainha foliar diminuta na base de um dos ramos da sinflorescência (Sendulsky \& Burman 1978).

\section{Paspalum decumbens Sw.}

Fig. 6d-e

Planta perene, decumbente. Lâminas lanceoladas, com estreitamento basal. Sinflorescência com um ramo terminal. Ráquis áptera 0,3-0,4 mm larg., glabra a inconspicuamente escabrosa nas margens; pedicelos inconspicuamente escabrosos. Espiguetas 1,8-2 mm compr., pareadas, glabras; gluma inferior reduzida; gluma superior áptera, 3-nervada; glabra, lema inferior áptero, 3-nervado, glabro, sem uma porção hialina no centro; pálea inferior ausente; antécio superior obovado, estramíneo na maturação.

Material examinado: Brasília, Parque Ecológico Bernardo Sayão, 15.XII.2016, f1., A.P.M. Lira-Gouvêa et al. 202 (UB).

Foi registrada em borda de mata. Coletada em floração em dezembro. Espécie nativa com ampla distribuição, com registros de ocorrência em todas as regiões do país (BFG 2018).

É caracterizada pela presença da gluma inferior e hábito decumbente. Mostra afinidade com P. nutans Lam., da qual se distingue pela ocorrência regular da gluma inferior, sempre mais longa que 1/6 do comprimento da espigueta. Em P. nutans, a ocorrência da gluma inferior é apenas ocasional (Denham 2005).
4. Paspalum erianthum Nees ex Trin. Fig. 3k-1

Planta perene, cespitosa. Lâminas lanceoladas, com estreitamento basal. Sinflorescência com 3-12 ramos alternos. Ráquis áptera $0,5-0,7 \mathrm{~mm}$ larg., glabra a inconspicuamente escabrosa nas margens; pedicelos inconspicuamente escabrosos. Espiguetas 3,5-4 mm compr., pareadas, pilosas; gluma inferior ausente; gluma superior áptera, 5-nervada, com tricomas tuberculados; lema inferior áptero, 3-nervado, com tricomas tuberculados, sem uma porção hialina no centro; pálea inferior ausente; antécio superior elíptico, estramíneo na maturação.

Material examinado: Brasília, Parque Ecológico Bernardo Sayão, 27.X.2016, fl., A.P.M. Lira-Gouvêa et al. 170 (UB); 27.X.2016, fl., A.P.M. Lira-Gouvêa et al. 176 (UB); 30.XI.2016, fl., A.P.M. Lira-Gouvêa et al. 191 (UB).

Foi registrada em cerrado sentido restrito e campo limpo. Coletada em floração em outubro e novembro. Paspalum erianthum é uma espécie nativa, com ocorrência registrada em todas as regiões do Brasil (BFG 2018).

Apresenta afinidade morfológica com $P$. ammodes (Morrone et al. 2004) e a distinção foi comentada acima, sob essa outra espécie.

\section{Paspalum eucomum Nees ex Trin.}

Figs. 2a-b; 5d-g

Planta perene, cespitosa. Lâminas filiformes, sem estreitamento basal. Sinflorescência com 2 ramos conjugados ou subconjugados, raro um terceiro ramo abaixo do par conjugado. Ráquis alada 1,5-3 mm larg., margens glabras; pedicelos das espiguetas com tricomas estrelados. Espiguetas 1,5-2 mm compr., solitárias, pilosas; gluma inferior ausente; gluma superior áptera, 3-nervada, densamente pilosa, às vezes com tricomas tuberculados purpúreos no dorso e margens; lema inferior áptero, 3-nervado, com tricomas tuberculados, sem uma porção hialina no centro; pálea inferior ausente; antécio superior obovado, esverdeado a estramíneo na maturação.

Material examinado: Brasília, Parque Ecológico Bernardo Sayão, 1.V.2017, fl., A.P.M. Lira-Gouvêa et al. 283 (UB); 1.V.2017, fl., A.P.M. Lira-Gouvêa et al. 285 (UB).

Registrada em cerrado sentido restrito e áreas antropizadas. Coletada em floração em maio. Espécie endêmica do Brasil, ocorrendo somente nas regiões Centro-Oeste, Sudeste e Sul, exclusivamente no bioma Cerrado (BFG 2018).

Paspalum eucomum é relacionada a $P$. stellatum Humb. \& Bonpl. ex Flüggé, pela ráquis 
alada e espiguetas densamente pilosas (Denham et al. 2002; Bonasora et al. 2015).

O caráter "pedicelos com tricomas estrelados", muito citado como exclusivo de $P$. stellatum (Denham et al. 2002; Oliveira \& Valls 2001; Reis 2014) e que inclusive inspirou o epíteto específico, também foi encontrado nos exemplares de P. eucomum. Estas espécies são distinguidas pela ráquis, mais larga em
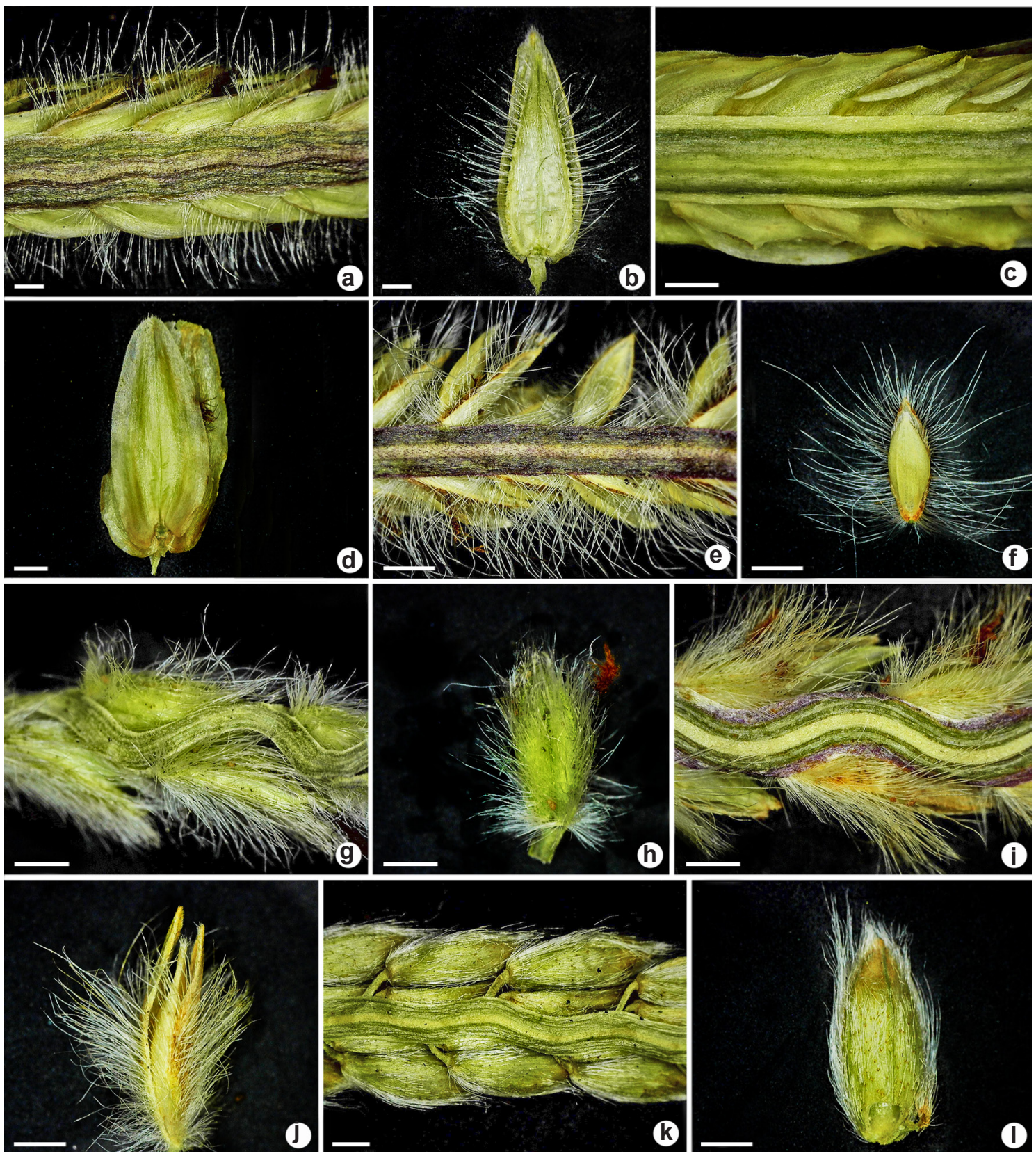

Figura 3 - a-b. Paspalum pectinatum - a. ráquis; b. espigueta. c-d. P. imbricatum - c. ráquis; d. espigueta. e-f. P. polyphyllume. ráquis; f. espigueta. g-h. P. ammodes - g. ráquis; h. espigueta. i-j. P. guttatum -i. ráquis; j. espigueta. k-1. P. erianthum-k. ráquis; 1. espigueta. (a-b. Lira-Gouvêa 170b; c-d. Lira-Gouvêa 165; e-f. Lira-Gouvêa 162; g-h. Lira-Gouvêa 194; i-j. LiraGouvêa 171; k-1. Lira-Gouvêa 176). Barras: 1mm

Figure 3 - a-b. Paspalum pectinatum - a. rachis; b. spikelet; c-d. P. imbricatum - c. rachis; d. spikelet. e-f. P. polyphyllum - e. rachis; f. spikelet. g-h. P. ammodes - g. rachis; h. spikelet. i-j. P. guttatum - i. rachis; j. spikelet. k-1. P. erianthum-k. rachis; 1. spikelet. (a-b. Lira-Gouvêa 170b; c-d. Lira-Gouvêa 165; e-f. Lira-Gouvêa 162; g-h. Lira-Gouvêa 194; i-j. Lira-Gouvêa 171; k-1. Lira-Gouvêa 176). Bars: 1mm 
P. stellatum (4-10 mm) (Bonasora et al. 2015). No PEBS, P. eucomum apresentou ráquis de 1,5-3 mm e $P$. stellatum de 6-8 $\mathrm{mm}$.

\section{Paspalum foliiforme S. Denham Fig. $6 \mathrm{j}-\mathrm{k}$}

Planta perene, cespitosa. Lâminas lineares, com leve estreitamento basal. Sinflorescência com um ramo terminal linear, às vezes arqueado. Ráquis alada 4,5-7,5 mm larg., margens glabras; pedicelos inconspicuamente pilosos. Espiguetas 5-6,1 mm compr., solitárias, pilosas; gluma inferior reduzida; gluma superior áptera, 5-nervada, pilosa; lema inferior áptero, 5-nervado, piloso, sem uma porção hialina no centro; pálea inferior presente; antécio superior elíptico, estramíneo na maturação. Material examinado: Brasília, Parque Ecológico Bernardo Sayão, 6.IV.2016, fl., A.P.M. Lira-Gouvêa et al. 131 (UB); 13.V.2016, fl., A.P.M. Lira-Gouvêa et al. 137 (UB).

Foi registrada em cerrado sentido restrito. Coletada em floração em abril e maio. Espécie nativa, com ampla distribuição, com registros de ocorrência em todas as regiões do país, exceto a Região Sul (BFG 2018).

Paspalum foliiforme é caracterizada pela sinflorescência com um ramo terminal, no que se relaciona a $P$. thrasyoides e P. glaziovii, distinguindo-se pela ráquis glabra, enquanto estas apresentam ráquis com margens pilosas.

\section{Paspalum gardnerianum Nees Figs. 2d; 6m}

Planta perene, cespitosa. Lâminas linear-lanceoladas, sem estreitamento basal. Sinflorescência com 2-6 ramos alternos. Ráquis áptera $0,5-0,7 \mathrm{~mm}$ larg., inconspicuamente escabrosa nas margens; pedicelos com tricomas mais longos que o comprimento da espigueta. Espiguetas 1,5-1,8 mm compr., pareadas, glabras a esparsamente pilosas; gluma inferior ausente; gluma superior ausente; lema inferior áptero, 3-nervado, glabro a esparsamente piloso, sem uma porção hialina no centro; pálea inferior ausente; antécio superior elíptico a obovoide, castanho claro a escuro na maturação.

Material examinado: Brasília, Parque Ecológico Bernardo Sayão, 13.I.2016, fl., A.P.M. Lira-Gouvêa et al. 1 (UB); 6.IV.2016, fl., A.P.M. Lira-Gouvêa et al. 121 (UB); 13.V.2016, fl., A.P.M. Lira-Gouvêa et al. 136 (UB); 13.V.2016, fl., A.P.M. Lira-Gouvêa et al. 139 (UB); 16.VII.2016, fl., A.P.M. Lira-Gouvêa et al. 151 (UB); 6.VIII.2016, fl., A.P.M. Lira-Gouvêa et al. 156 (UB); 15.XII.2016, fl., A.P.M. Lira-Gouvêa et al. 204 (UB); 15.XII.2016, fl., A.P.M. Lira-Gouvêa et al. 205 (UB); 21.XII.2016, fl., A.P.M. Lira-Gouvêa et al. 213 (UB).
Foi registrada em campo limpo, campo sujo, campo de murundus e áreas antropizadas. Coletada em floração durante o ano todo. No Brasil ocorre em todas as regiões, exceto na Região Sul (BFG 2018).

Espécie com morfologia muito variável, no que toca à pilosidade dos órgãos vegetativos e à coloração dos antécios ao longo da maturação (Nicola et al. 2014). Frequente no PEBS, é reconhecida pela presença de tricomas longos e dourados na base dos pedicelos, espiguetas sem glumas e antécio superior castanho, fortemente papiloso. Pode ser confundida com $P$. reduncum, cujos caracteres distintivos são discutidos adiante, nos comentários sobre essa outra espécie.

8. Paspalum geminiflorum Steud. Figs. 2g; 4a-e Planta perene, cespitosa. Lâminas linear-lanceoladas, sem estreitamento basal. Sinflorescência com 1-4 ramos alternos. Ráquis áptera 0,6-0,8 mm larg., glabra nas margens, pedicelos glabros. Espiguetas 2,8-3,2 mm compr., pareadas, glabras; gluma inferior reduzida, presente apenas em uma espigueta do par; gluma superior áptera, 5-nervada, ornamentada por retículo de linhas irregulares de papilas, glabra; lema inferior áptero, 3-nervado, ornamentada por linhas irregulares de papilas, glabro, sem uma porção hialina no centro; pálea inferior ausente; antécio superior elíptico a obovoide, castanho escuro na maturação.

Material examinado: Brasília, Parque Ecológico Bernardo Sayão, 21.IV.2017, fl., A.P.M. Lira-Gouvêa et al. 271 (UB); 21.IV.2017, fl., A.PM. Lira-Gouvêa et al. 275 (UB).

Foi registrada em campo sujo antropizado. Coletada em floração em abril. Espécie nativa de ampla distribuição, com registros de ocorrência em todas as regiões do Brasil (BFG 2018).

Não há registro da presença da gluma inferior nas espiguetas de $P$. geminiflorum em trabalhos anteriores (Oliveira \& Valls 2001; Oliveira 2004; Oliveira \& Valls 2008). Os materiais de $P$. geminiflorum incorporados ao UB e CEN (cerca de 40 exemplares) foram analisados e também não a apresentam, mas esta característica foi observada ao menos em parte das espiguetas nos exemplares do PEBS (Fig. 4e).

Paspalum geminiflorum distingue-se das demais espécies por apresentar gluma superior e lema inferior ornamentados em direção ao ápice por retículo de linhas irregulares de papilas translúcidas. 


\section{Paspalum glaziovii (A.G. Burm.) S. Denham}

Figs. $2 \mathrm{j}$; $6 \mathrm{~h}-\mathrm{i}$

Planta perene, cespitosa. Lâminas linear-lanceoladas, sem estreitamento basal. Sinflorescência com um ramo terminal linear, às vezes arqueado. Ráquis alada 3-3,5 mm larg., margens pilosas com tricomas não tuberculados alvos, dorso piloso; pedicelos inconspicuamente pilosos. Espiguetas 2,5-3,2 mm compr., solitárias, pubescentes a pilosas; gluma inferior ausente; gluma superior áptera, 3-nervada, pubescente; lema inferior áptero, 5-nervado, margens ciliadas com 2 pelos no ápice maiores que os demais, sem uma porção hialina no centro; pálea inferior presente; antécio superior estreitamente elíptico, estramíneo na maturação.

Material examinado: Brasília, Parque Ecológico Bernardo Sayão, 6.IV.2016, fl., A.P.M. Lira-Gouvêa et al. 108 (UB).

Foi registrada em campo limpo. Coletada em floração em abril. Espécie endêmica do Brasil, ocorre somente na Região Centro-Oeste (BFG 2018).

Paspalum glaziovii difere de $P$. thrasyoides por apresentar tricomas não tuberculados alvos nas margens da ráquis, enquanto a segunda apresenta ráquis com tricomas tuberculados dourados em suas margens.
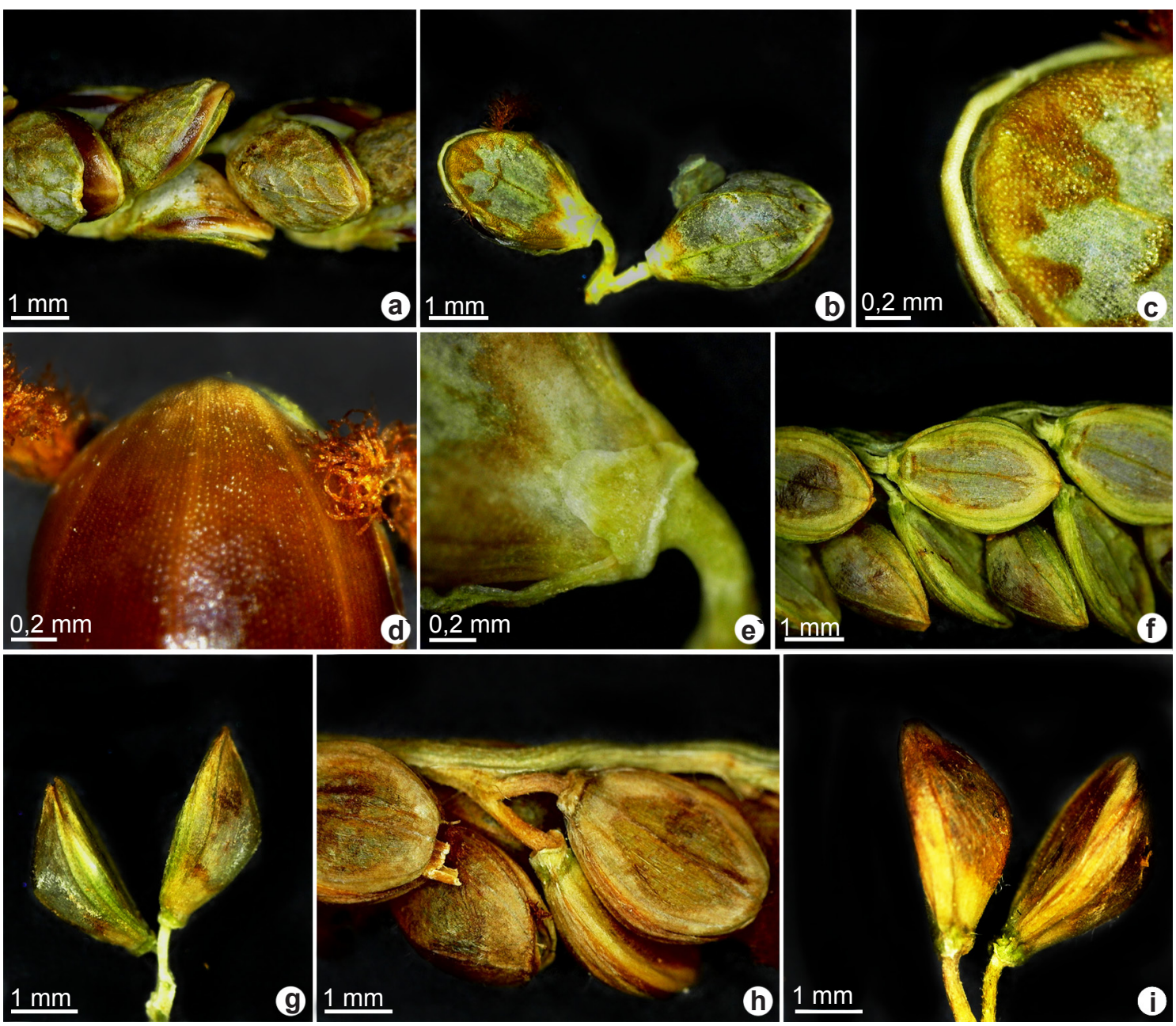

Figura 4 -a-e. Paspalum geminiflorum - a. sinflorescência; b. espiguetas pareadas; c. lema inferior ornamentado; d. antécio superior castanho escuro; e. gluma inferior reduzida. f-g. $P$. plicatulum - f. sinflorescência; g. espiguetas pareadas. h-i. $P$. rojasii - h. sinflorescência; i. espiguetas pareadas. (a-e. Lira-Gouvêa 271; f-g. Lira-Gouvêa 222; h-i. Lira-Gouvêa 224). Figure 4 - a-e. Paspalum geminiflorum - a. synflorescence; b. spikelets in pairs; c. ornate lower lemma; d. dark brown upper anthecium; e. reduced lower glume. f-g. P. plicatulum -f. synflorescence; g. spikelets in pairs. h-i. P. rojasii-h. sinflorescence; i. spikelets in pairs. (a-e. Lira-Gouvêa 271; f-g. Lira-Gouvêa 222; h-i. Lira-Gouvêa 224). 


\section{Paspalum guttatum Trin. $\quad$ Figs. $2 \mathrm{k}$; $3 \mathrm{i}-\mathrm{j}$}

Planta perene, cespitosa. Lâminas lineares, com leve estreitamento basal. Sinflorescência com 2 ramos subconjugados, raro um terceiro pouco abaixo. Ráquis curto-alada 1-1,3 mm larg., margens glabras; pedicelos das espiguetas sem tricomas estrelados. Espiguetas 3-4,2 mm compr., solitárias, pilosas; gluma inferior ausente; gluma superior áptera, 5-nervada, densamente pilosa, às vezes com tubérculos purpúreos; lema inferior áptero, 5-nervado, com tricomas tuberculados, sem uma porção hialina no centro; pálea inferior ausente; antécio superior elíptico, estramíneo na maturação.

Material examinado: Brasília, Parque Ecológico Bernardo Sayão, 27.X.2016, fl., A.P.M. Lira-Gouvêa et al. 188 (UB); 30.XI.2016, fl., A.P.M. Lira-Gouvêa et al. 194 (UB); 1.XII.2017, fl., A.P.M. Lira-Gouvêa et al. 291 (UB).

Foi registrada em cerrado sentido restrito. Coletada em floração em outubro e novembro. Endêmica do Brasil, ocorrendo no Centro-Oeste, Sudeste e Sul (BFG 2018).

Mostra afinidade com P. ammodes (Denham et al. 2002; Morrone et al. 2004), por serem as únicas do grupo Eriantha com espiguetas solitárias, porém a distinção mais geral foi discutida acima sob essa outra espécie. Adicionalmente, cabe destacar que as pontuações purpúreas, resultantes de papilas isoladas ou concrescentes situadas entre as nervuras, que dão origem ao epíteto específico, e a tendência ao enrolamento das folhas senescentes (Sendulsky \& Burman 1978) são características típicas de $P$. guttatum.

\section{Paspalum hyalinum Nees ex Trin. Fig. 61} Planta perene, cespitosa. Lâminas linearlanceoladas, com leve estreitamento basal. Sinflorescência com 2-4 ramos alternos. Ráquis áptera $0,2-0,3 \mathrm{~mm}$ larg., inconspicuamente escabrosa nas margens; pedicelos inconspicuamente escabrosos. Espiguetas 1,2-1,5 mm compr., solitárias, glabras; gluma inferior ausente; gluma superior áptera, 2-nervada, glabra, hialina; lema inferior áptero, 2-nervado, glabro, com porção hialina no centro; pálea inferior ausente; antécio superior elíptico, estramíneo na maturação.

Material examinado: Brasília, Parque Ecológico Bernardo Sayão, 6.VIII.2016, fl., A.P.M. Lira-Gouvêa et al. 159 (UB).

Registrada em campo sujo e campo sujo antropizado. Coletada em floração em agosto. Ocorre em todas as regiões do Brasil (BFG 2018).
Caracteriza-se pelas espiguetas glabras, com lema inferior apresentando uma porção hialina no centro, o que a distingue de todas as demais espécies de Paspalum e deu origem ao seu epíteto específico (Judziewicz 1990; Oliveira \& Valls 2001; Sendulsky \& Burman 1980; Zuloaga \& Morrone 2005).

\section{Paspalum imbricatum Filg.}

Fig. 3c-d

Planta perene, cespitosa. Lâminas lineares, sem estreitamento basal. Sinflorescência com 4-5 ramos alternos. Ráquis curto-alada 1,3-1,8 $\mathrm{mm}$ larg., margens glabras; pedicelos glabros. Espiguetas 7-8 mm compr., solitárias, glabras; gluma inferior ausente; gluma superior com margens aladas, levemente cordada na base, 3-nervada, glabra; lema inferior alado, 3-nervado, glabro, sem uma porção hialina no centro; pálea inferior ausente; antécio superior elíptico, estramíneo na maturação.

Material examinado: Brasília, Parque Ecológico Bernardo Sayão, 6.IV.2016, fl., A.P.M. Lira-Gouvêa et al. 112 (UB); 6.VIII.2016, fl., A.PM. Lira-Gouvêa et al. 165 (UB).

Foi registrada em Vereda. Coletada em floração em abril e agosto. Paspalum imbricatum é típica de áreas úmidas (Felfili et al. 2007; Ribeiro 2011), com registros apenas na Região Centro-Oeste (BFG 2018) e pouco frequente nos levantamentos de flora realizados no DF.

Paspalum imbricatum é relacionada a $P$. pectinatum e P. cordatum pela gluma superior alada (Denham et al. 2002; Delfini et al. 2017). Se diferencia de P. cordatum por apresentar lema inferior glabro, enquanto em $P$. cordatum o lema inferior tem tricomas nas margens. A distinção de P. imbricatum e P. pectinatum é discutida adiante, sob $P$. pectinatum.

\section{Paspalum lineare Trin.}

Fig. $5 \mathrm{j}-\mathrm{k}$

Planta perene, cespitosa. Lâminas filiformes, sem estreitamento basal. Sinflorescência com 2 ramos terminais conjugados ou subconjugados. Ráquis áptera 0,4-0,6 mm larg., margens levemente escabrosas; pedicelos inconspicuamente escabrosos. Espiguetas 4-5 mm compr., solitárias, glabras ou com tricomas na base; gluma inferior ausente; gluma superior áptera, 5-nervada, glabra ou com tricomas na base; lema inferior áptero, 5-nervado, nervuras conspícuas, glabro ou com tricomas na base, sem uma porção hialina no centro; pálea inferior ausente; antécio superior elíptico, estramíneo na maturação. 

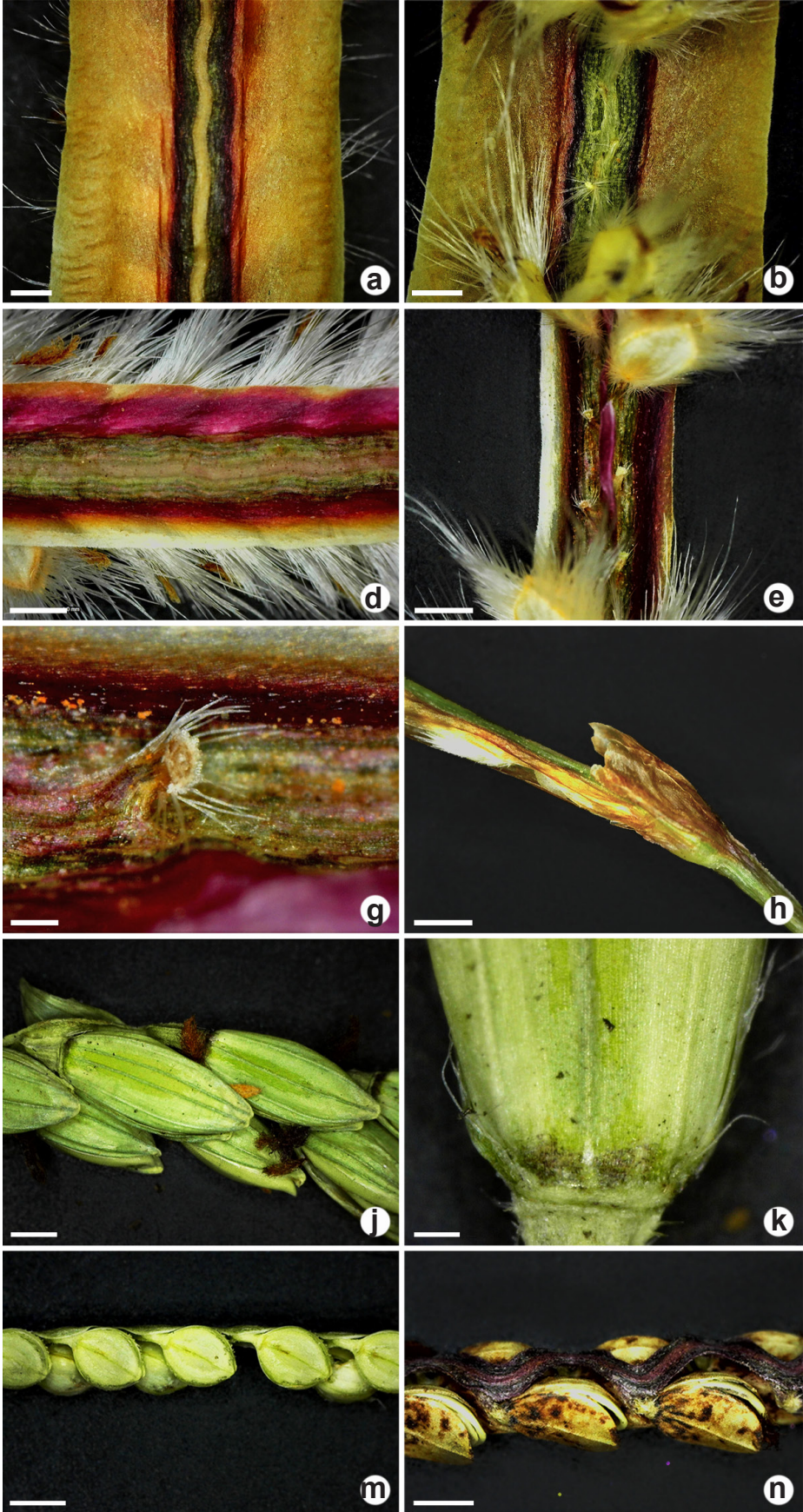

$\boldsymbol{k}$

(n)

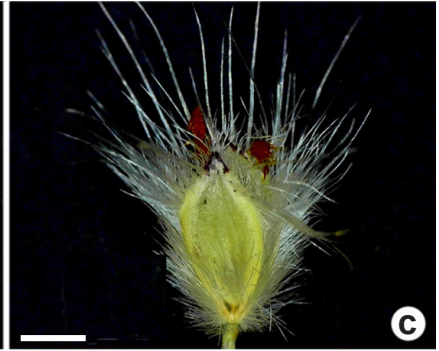

e)
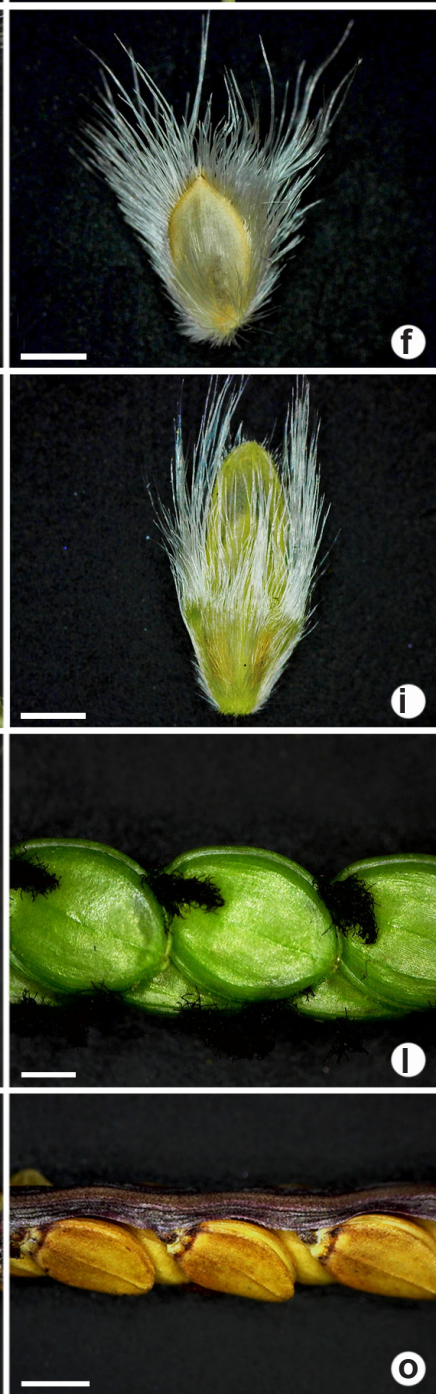

Figura 5 - a-c. Paspalum stellatum - a. ráquis alada; b. pedicelos com tricomas estrelados; c. espigueta. d-g. P. eucomumd. ráquis alada; e. pedicelos com tricomas estrelados; f. espigueta; g. detalhe do pedicelo. h-i. $P$. carinatum - h. estrutura semelhante a uma bainha na base do ramo; i. espigueta. j-k. P. lineare - j. sinflorescência; k. tricomas na base da espigueta. 1. P. notatum -1. sinflorescência. m. P. multicaule - $\mathrm{m}$. sinflorescência. n-o. P. maculosum -n. sinflorescência com espiguetas com manchas; o. sinflorescência com espiguetas sem manchas. (a-c. Lira-Gouvêa 267; d-g. Lira-Gouvêa 283; h- i. Valls 16767; j-k. Lira-Gouvêa 180; 1. Valls 16774; m. Lira-Gouvêa 119; n. Lira-Gouvêa 198; o. Lira-Gouvêa 227). Barras: 1mm Figure 5 - a-c. Paspalum stellatum - a. winged rachis; b. pedicels stellarly pilose; c. spikelet. d-g. P. eucomum - d. winged rachis; e. pedicels stellarly pilose; f. spikelet; g. detail of pedicel. h-i. P. carinatum - h. sheath-like membranaceous structure at the base of the raceme; i. spikelet. $\mathrm{j}$-k. P. lineare $-\mathrm{j}$. synflorescence; $\mathrm{k}$. trichomes at the base of the spikelets. 1. P. notatum -1. synflorescence. m. P. multicaule $-\mathrm{m}$. synflorescence. n-o. P. maculosum - n. synflorescence with spotted spikelets; o. synflorescence with non-spotted spikelets. (a-c. Lira-Gouvêa 267; d-g. LiraGouvêa 283; h- i. Valls 16767; j-k. Lira-Gouvêa 180; 1. Valls 16774; m. Lira-Gouvêa 119; n. Lira-Gouvêa 198; o. Lira-Gouvêa 227). Bars: 1mm 
Material examinado: Brasília, Parque Ecológico Bernardo Sayão, 27.X.2016, fl., A.P.M. Lira-Gouvêa et al. 172 (UB); 27.X.2016, fl., A.P.M. Lira-Gouvêa et al. 180 (UB).

Foi registrada em campo limpo úmido. Coletada em floração em outubro. Espécie nativa com registros de ocorrência em todas as regiões do Brasil (BFG 2018).

Paspalum lineare é uma espécie associada a áreas úmidas (Munhoz \& Felfili 2007; Zuloaga \& Morrone 2005). Oliveira \& Valls (2002) apontam a presença de tricomas na base da espigueta, caráter observado nos exemplares do PEBS (Fig. 5k), mas que pode ser variável, já que os tricomas são caducos. É caracterizada pela sinflorescência composta por 2 ramos unilaterais terminais conjugados e pelas espiguetas elípticas. As lâminas filiformes e os nós barbados auxiliam na identificação a campo.

\section{Paspalum maculosum Trin.}

Fig. 5n-o

Planta perene, cespitosa. Lâminas lineares a filiformes, sem estreitamento basal. Sinflorescência com 2 ramos conjugados ou subconjugados. Ráquis áptera 0,4-0,8 mm larg., margens glabras a inconspicuamente escabrosas; pedicelos inconspicuamente escabrosos. Espiguetas 2-2,8 mm compr., solitárias, glabras; gluma inferior ausente; gluma superior áptera, 5-nervada, com ou sem manchas vináceas irregularmente distribuídas, glabra; lema inferior áptero 3-nervado, apenas a nervura central conspícua, frequentemente com manchas vináceas irregularmente distribuídas, glabro, sem uma porção hialina no centro; pálea inferior ausente; antécio superior elíptico-obovado, esverdeado a estramíneo na maturação.

Material examinado: Brasília, Parque Ecológico Bernardo Sayão, 13.I.2016, fl., A.P.M. Lira-Gouvêa et al. 34 (UB); 18.I.2017, fl., A.P.M. Lira-Gouvêa et al. 227 (UB); 18.I.2017, fl., A.P.M. Lira-Gouvêa et al. 228 (UB); 25.II.2017, fl., A.P.M. Lira-Gouvêa et al. 264 (UB).

Foi registrada em campo limpo e vereda. Coletada em floração de dezembro a fevereiro. Registrada em todas as regiões do país (BFG 2018).

Espécie caracterizada pelas espiguetas com máculas (Canto-Dorow et al. 1996; Zuloaga et al. 2004; Oliveira et al. 2016). Embora Zuloaga et al. (2004) comentem que as máculas constituem um caráter variável, podendo ocorrer espiguetas sem máculas, este caráter costuma ser enfatizado nas chaves, o que pode dificultar a identificação da espécie.
Alguns exemplares analisados apresentam as máculas características (Fig. 5n), mas exemplares com espiguetas sem as máculas também ocorrem, os quais apresentam ráquis menos sinuosa (Fig. 5o) e espiguetas menores que os exemplares com máculas. Esta variação merece ser investigada com maior profundidade.

\section{Paspalum multicaule Poir.}

Fig. $5 \mathrm{~m}$

Planta anual, cespitosa. Lâminas lineares, sem estreitamento basal. Sinflorescência com 2 ramos conjugados ou levemente subconjugados. Ráquis áptera 0,6-0,8 mm larg., margens glabras a inconspicuamente escabrosas; pedicelos inconspicuamente escabrosos. Espiguetas 0,8-1 mm compr., solitárias, com tricomas glandulosos subglobosos; gluma inferior ausente; gluma superior áptera, 3-nervada, com tricomas glandulares subglobosos no dorso; lema inferior áptero, 3-nervado, apenas a nervura central conspícua, tricomas glandulares subglobosos no dorso, principalmente em direção ao ápice, sem uma porção hialina no centro; pálea inferior ausente; antécio superior suborbicular, estramíneo na maturação.

Material examinado: Brasília, Parque Ecológico Bernardo Sayão, 6.IV.2016, fl., A.P.M. Lira-Gouvêa et al. $118 b$ (UB); 6.IV.2016, fl., A.P.M. Lira-Gouvêa et al. 119 (UB).

Foi registrada em cerrado sentido restrito. Coletada em floração em abril. Registrada em todas as regiões, exceto na Região Sul (BFG 2018).

Paspalum multicaule é a única espécie anual de Paspalum coletada no PEBS. Pode ser identificada por suas espiguetas diminutas (0,8-1 mm compr.), suborbiculares, com tricomas glandulosos subglobosos concentrados na porção distal da gluma superior.

\section{Paspalum notatum Flüggé}

Fig. 51

Planta perene, reptante, estolonífera, estolhos com entrenós muito curtos cobertos pelas bainhas foliares. Lâminas lanceoladas a lineares, sem estreitamento basal. Sinflorescência com 2 ramos conjugados no ápice do colmo florífero. Ráquis áptera 0,8-1,1 mm larg., margens escabrosas; pedicelos inconspicuamente escabrosos. Espiguetas 3-3,5 mm compr., solitárias, glabros; gluma inferior ausente; gluma superior áptera, 3-5-nervada, glabra; lema inferior áptero, 3-5 nervado, glabro, sem uma porção hialina no centro; pálea inferior ausente; antécio superior suborbicular, estramíneo na maturação. 

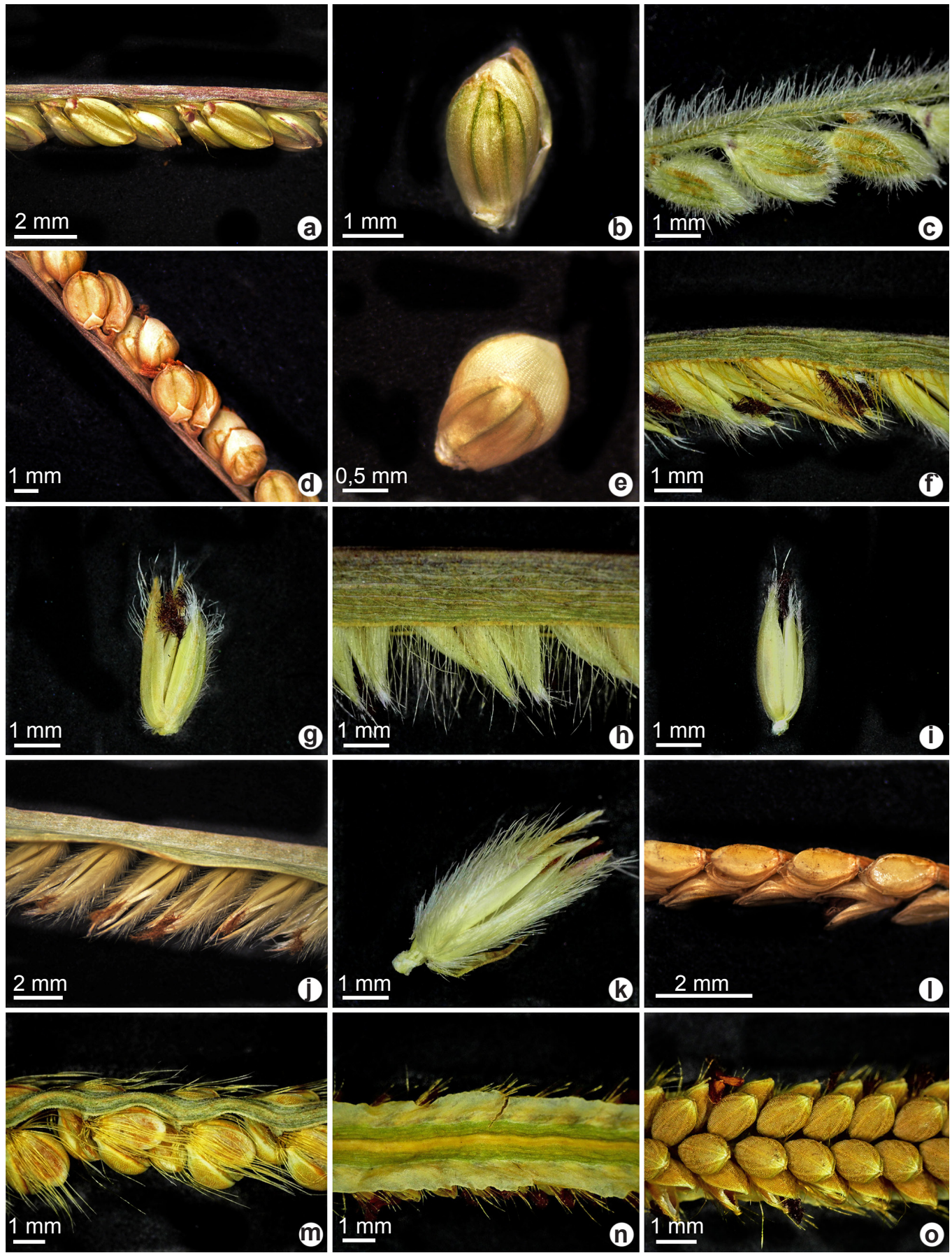

Figura 6-a-c. Paspalum pilosum - a. sinflorescência; b. espigueta; c. sinflorescência com morfologia anormal. d-e. P. decumbens d. sinflorescência; e. espigueta. f-g. P. thrasyoides -f. sinflorescência; g. espigueta. h-i. P. glaziovii -h. sinflorescência; i. espigueta. $\mathrm{j}$-k. P. foliiforme - j. sinflorescência; k. espigueta. 1. P. hyalinum-1. sinflorescência. m. $P$. gardnerianum-1. sinflorescência. n-o. $P$. reduncum -n. ráquis; o. espiguetas dispostas na ráquis. (a-b. Lira-Gouvêa 210; c. Lira-Gouvêa 107; d-e Lira-Gouvêa 202; f-g. LiraGouvêa 181; h-i. Lira-Gouvêa 108; j-k. Lira-Gouvêa 131; 1. Lira-Gouvêa 159; m. Lira-Gouvêa 121; n-o. Lira-Gouvêa 115b). Figure 6-a-c. Paspalum pilosum -a. synflorescence; b. spikelet; c. synflorescence with abnormal morphology. d-e. P. decumbens - d. synflorescence; e. spikelet. f-g. P. thrasyoides - f. synflorescence; g. spikelet. h-i. P. glaziovii - h. synflorescence; i. spikelet. $\mathrm{j}$-k. P. foliiforme $-\mathrm{j}$. synflorescence; $\mathrm{k}$. spikelet. 1. P. hyalinum -1. synflorescence. m. P. gardnerianum -1. synflorescence. n-o. P. reduncum - n. rachis; o. rachis with spikelets. (a-b. Lira-Gouvêa 210; c. Lira-Gouvêa 107; d-e Lira-Gouvêa 202; f-g. Lira-Gouvêa 181; h-i. Lira-Gouvêa 108; j-k. Lira-Gouvêa 131; 1. Lira-Gouvêa 159; m. Lira-Gouvêa 121; n-o. Lira-Gouvêa 115b). 
Material examinado: Brasília, Parque Ecológico Bernardo Sayão, 18.I.2018, fl., J.F.M. Valls \& M.W.S. Sousa 16774 (CEN).

Foi registrada em campo sujo. Coletada em floração em janeiro. Ocorre em todas as regiões do Brasil (BFG 2018).

Popularmente conhecida como gramabatatais, ou grama-forquilha, é uma espécie comumente usada como forrageira ou em gramados (Zuloaga et al. 2004). Apresenta grande variabilidade morfológica, sendo bastante distinta pela presença de estolhos com entrenós extremamente curtos, revestidos pelas bainhas foliares.

\section{Paspalum pectinatum Nees ex Trin.}

Figs. 2h; 3a-b

Planta perene, cespitosa ou cespitosorizomatosa. Lâminas lineares, sem estreitamento basal. Sinflorescência com 2-3 ramos subconjugados. Ráquis curto-alada 2,2-2,5 mm larg., margens inconspicuamente escabrosas; pedicelos glabros. Espiguetas 6,5-8 mm compr., solitárias, pilosas; gluma inferior ausente; gluma superior com margens aladas, cordadas na base, 3-nervada, glabra; lema inferior áptero, 3-nervado, com tricomas tuberculados nas margens que ultrapassam as margens da gluma superior, sem uma porção hialina no centro; pálea inferior ausente; antécio superior elíptico, estramíneo na maturação.

Material examinado: Brasília, Parque Ecológico Bernardo Sayão, 27.X.2016, fl., A.P.M. Lira-Gouvêa et al. 172 (UB); 27.X.2016, fl., A.P.M. Lira-Gouvêa et al. 180 (UB).

Foi registrada em campo sujo e cerrado sentido restrito. Coletada em floração em outubro. Ocorre em todas as regiões do país (BFG 2018).

Paspalum pectinatum está relacionada a $P$. imbricatum e $P$. cordatum pela gluma superior alada. Paspalum pectinatum e P. imbricatum diferenciam-se pela sinflorescência com dois a três ramos subconjugados e lema inferior ciliado com tricomas de base tuberculada em $P$. pectinatum e sinflorescência com 4-5 ramos alternos e lema glabro em $P$. imbricatum (Denham et al. 2002; Delfini et al. 2017).

Diferencia-se de P. cordatum (Delfini et al. 2017) pelo número de ramos por sinforescência (2-3 ramos em $P$. pectinatum e 5-10 ramos em $P$. cordatum) e pelo comprimento dos tricomas no lema inferior (excedem as margens da gluma superior em $P$. pectinatum e não as excedem em P. cordatum).
18. Paspalum pilosum Lam.

Fig. 6a-c

Planta perene, decumbente, rizomas curtos. Lâminas linear-lanceoladas, sem estreitamento basal. Sinflorescência com 1-2 ramos terminais ou alternos. Ráquis áptera 0,5-1 mm larg., com tricomas tuberculados esparsos nas margens; pedicelos inconspicuamente escabrosos. Espiguetas 2,5-3 mm compr., pareadas, glabras; gluma inferior presente, mas reduzida, podendo ser distinta nas duas espiguetas de cada par; gluma superior áptera, 5-nervada; lema inferior áptero, 5-nervado, glabro, sem uma porção hialina no centro; pálea inferior presente; antécio superior elíptico, estramíneo a esverdeado na maturação.

Material examinado: Brasília, Parque Ecológico Bernardo Sayão, 13.I.2016, fl., A.P.M. Lira-Gouvêa et al. 3 (UB); 13.I.2016, fl., A.P.M. Lira-Gouvêa et al. 52 (UB); 6.IV.2016, fl., A.P.M. Lira-Gouvêa et al. 107 (UB); 15.XII.2016, fl., A.P.M. Lira-Gouvêa et al. 203 (UB); 15.XII.2016, fl., A.P.M. Lira-Gouvêa et al. 210 (UB).

Foi registrada em campo limpo, campo sujo e vereda. Coletada em floração de dezembro a abril. Distribuída em todas as regiões do país (BFG 2018).

Reconhecida vegetativamente pelo hábito decumbente. A gluma inferior, embora reduzida, estava presente em grande parte dos espécimens analisados, podendo ser distinta nas duas espiguetas de cada par.

Foi encontrado um indivíduo de $P$. pilosum com morfologia anormal provocada por infecção fúngica, apresentando espiguetas teratológicas, densamente pilosas (Fig. 6c). Esta teratologia provoca alterações morfológicas tão marcantes, que dois nomes distintos, Thrasya venezuelana Chase e $T$. villosa Hitchc. foram atribuídos no passado a essas formas, mais adiante transferidas a Paspalum, respectivamente sob $P$. peregrinum A.G. Burm. $\&$ Filg. e P. venezuelanum (Chase) A.G. Burm. Esta questão foi minuciosamente esclarecida por Denham \& Aliscioni (2003).

19. Paspalum plicatulum Michx.

Fig. 4f-g

Planta perene, cespitosa. Lâminas linear-lanceoladas, sem estreitamento basal. Sinflorescência com 3-5 ramos alternos. Ráquis áptera, 0,5-0,7 mm larg., glabra nas margens; pedicelos inconspicuamente escabrosos. Espiguetas 2-2,5 mm compr., pareadas, glabras; gluma inferior ausente; gluma superior áptera, 5-nervada, glabra; lema inferior áptero, 5-nervado, não variegado, glabro, sem uma porção hialina no centro; pálea 
inferior ausente; antécio superior obovoide, castanho escuro na maturação.

Material examinado: Brasília, Parque Ecológico Bernardo Sayão, 18.I.2017, f1., A.P.M. Lira-Gouvêa et al. 222 (UB); 18.I.2017, fl., A.P.M. Lira-Gouvêa et al. 232 (UB).

Foi registrada em campo sujo e campo sujo antropizado. Coletada em floração em janeiro. Existem registros de sua ocorrência em todas as regiões do Brasil (BFG 2018).

Paspalum plicatulum é morfologicamente relacionada a $P$. rojasii Hack. e $P$. geminiflorum, pelo antécio superior liso, castanho escuro e brilhante. Os caracteres usados por diferentes autores para a separação destas espécies, vegetativos ou reprodutivos, frequentemente se sobrepõem (Barreto 1956; Oliveira 2004).

Alguns autores utilizam o comprimento da espigueta na distinção de P. plicatullum e P. rojasii (Oliveira \& Valls 2001; Oliveira 2004), caráter este que também foi utilizado para delimitar estas espécies neste trabalho. Paspalum plicatulum se diferencia de $P$. geminiflorum por apresentar gluma superior e lema inferior sem ornamentação com linhas de papilas, estruturas que em P. geminiflorum são muito conspícuas.

\section{Paspalum polyphyllum Nees Figs. 21; 3e-f}

Planta perene, cespitosa. Lâminas linear lanceoladas, sem estreitamento basal. Sinflorescência com 2-4 ramos alternos. Ráquis curto-alada 1-1,2 mm larg., margens pilosas, pedicelos pilosos. Espiguetas 2,3-3 mm compr., pareadas, pilosas; gluma inferior ausente; gluma superior áptera, 3-nervada, com tricomas tuberculados nas margens; lema inferior áptero, 3-nervado, com tricomas tuberculados nas margens, sem uma porção hialina no centro; pálea inferior ausente; antécio superior elíptico, estramíneo na maturação.

Material examinado: Brasília, Parque Ecológico Bernardo Sayão, 6.VII.2016, fl., A.P.M. Lira-Gouvêa et al. 162 (UB); 21.XII.2016, fl., A.P.M. Lira-Gouvêa et al. 215 (UB).

Foi registrada em campo de murundu, campo sujo e campo limpo antropizado. Coletada em floração em agosto e dezembro. Ocorre em todas as regiões do país, exceto na Região Norte (BFG 2018).

Quando em época de floração, P. polyphyllum pode ser reconhecido a campo pelas folhas distribuídas ao longo do colmo, por suas inflorescências alvas, densamente pilosas e ráquis curto-alada castanha a arroxeada (Fig. 3e).
Caracteriza-se pelas espiguetas pareadas, com gluma superior e lema inferior de margens pilosas, compostas por tricomas longos e desiguais de base tuberculada.

Denham et al. (2002) sinonimizam $P$. bicilium Mez a P. polyphyllum, mas Reis et al. (2015) discordam da sininomização e relacionam os caracteres distintivos destas espécies. Paspalum bicilium não foi encontrada no PEBS.

\section{Paspalum reduncum Nees ex Steud.}

Figs. 2e-f; 6n-o

Planta perene, cespitosa. Lâminas lanceoladas, com estreitamento basal. Sinflorescência com 4-12 ramos alternos. Ráquis alada 3-3,2 $\mathrm{mm}$ larg., margens glabras; pedicelos com tricomas mais curtos que o comprimento da espigueta. Espiguetas 1,2-1,5 mm compr., pareadas, glabras a esparsamente pilosas; gluma inferior ausente; gluma superior ausente; lema inferior áptero, 3-nervado, glabro, sem uma porção hialina no centro; pálea inferior ausente; antécio superior obovoide, castanho claro na maturação.

Material examinado: Brasília, Parque Ecológico Bernardo Sayão, 16.IV.2016, fl., A.P.M. Lira-Gouvêa et al. 115 b (UB); 6.VIII.2016, fl., A.P.M. Lira-Gouvêa et al. 155 (UB); 21.IV.2017, f1., A.P.M. Lira-Gouvêa et al. 276 (UB).

Foi registrada em campo sujo e campo sujo antropizado. Coletada em floração em abril e agosto. Existem registros de ocorrência em Goiás e no Distrito Federal (BFG 2018), além de Minas Gerais (Nicola et al. 2014).

Pode ser confundida com $P$. gardnerianum pela ausência da gluma superior e antécio superior papiloso. Porém, $P$. reduncum apresenta ráquis alada e pedicelos com tricomas mais curtos que o comprimento da espigueta. Paspalum gardnerianum possui ráquis áptera e tricomas dourados mais longos que o comprimento da espigueta.

\section{Paspalum rojasii Hack. $\quad$ Figs. $2 \mathrm{c}$; $4 \mathrm{~h}-\mathrm{i}$}

Planta perene, cespitosa. Lâminas linear-lanceoladas, sem estreitamento basal. Sinflorescência com 2-6 ramos alternos. Ráquis áptera, 0,5-0,6 $\mathrm{mm}$ larg., glabra a inconspicuamente escabrosa nas margens; pedicelos inconspicuamente escabrosos. Espiguetas 3-3,5 mm compr., pareadas, inconspicuamente pilosas; gluma inferior ausente; gluma superior áptera, 5-nervada, glabra a esparsamente pilosa na porção central; lema inferior áptero, 5-nervado, não variegado, glabro, sem uma 
porção hialina no centro; pálea inferior ausente; antécio superior obovoide, liso e castanho escuro na maturação.

Material examinado: Brasília, Parque Ecológico Bernardo Sayão, 18.I.2017, fl., A.P.M. Lira-Gouvêa et al. 224 (UB); 16.II.2017, fl., A.P.M. Lira-Gouvêa et al. 254 (UB).

Foi registrada em campo sujo antropizado. Coletada em floração em janeiro e fevereiro. Espécie nativa, com registros de ocorrência nas regiões Nordeste, Centro-Oeste, Sudeste e Sul (BFG 2018).

Apresenta afinidade morfológica com $P$. plicatulum e $P$. geminiflorum, cujos caracteres distintivos foram discutidos nos comentários sob essas espécies.

23. Paspalum stellatum Humb. \& Bonpl. ex Flüggé

Figs. 2i; 5a-c

Planta perene, cespitosa. Lâminas filiformes, com estreitamento basal. Sinflorescência com um ramo ou dois ramos conjugados, eventualmente ainda um terceiro inserido mais abaixo. Ráquis alada 6-8 mm larg., margens glabras; pedicelos das espiguetas com tricomas estrelados. Espiguetas 2-3 mm compr., solitárias, pilosas; gluma inferior ausente; gluma superior áptera, 3-nervada, densamente pilosa, às vezes com tricomas tuberculados; lema inferior áptero, 3-nervado, com pilosidade serícea, sem uma porção hialina no centro; pálea inferior ausente; antécio superior elíptico a obovado, esverdeado a estramíneo na maturação.

Material examinado: Brasília, Parque Ecológico Bernardo Sayão, 6.IV.2016, fl., A.P.M. Lira-Gouvêa et al. 116 (UB); 16.VII.2016, fl., A.P.M. Lira-Gouvêa et al. 154 (UB); 6.VIII.2016, fl., A.P.M. Lira-Gouvêa et al. 158 (UB); 6.VIII.2016, fl., A.P.M. Lira-Gouvêa et al. 161 (UB); 27.X.2016, fl., A.P.M. Lira-Gouvêa et al. 173 (UB); 21.IV.2017, fl., A.P.M. Lira-Gouvêa et al. 267 (UB).

Foi registrada em cerrado sentido restrito, campo sujo e áreas antropizadas. Coletada em floração durante o ano todo. Ocorre em todas as regiões do país (BFG 2018).

Paspalum stellatum pode ser confundida com P. eucomum. A distinção de ambas foi discutida sob P. eисотит.

\section{Paspalum thrasyoides (Trin.) S. Denham}

Fig. 6f-g

Planta perene, com rizomas curtos. Lâminas linear-lanceoladas, sem estreitamento basal. Sinflorescência com um ramo terminal linear, às vezes arqueado. Ráquis alada 2-3 mm larg., margens pilosas com tricomas tuberculados dourados, dorso glabro; pedicelos inconspicuamente pilosos. Espiguetas 3-3,5 mm compr., solitárias, pilosas; gluma inferior presente, mas reduzida; gluma superior áptera, 3-nervada, pubescente; lema inferior áptero, 5-nervado, densamente ciliado nas margens do 1/3 apical, sem uma porção hialina no centro; pálea inferior presente; antécio superior elíptico, estramíneo na maturação.

Material examinado: Brasília, Parque Ecológico Bernardo Sayão, 27.X.2016, fl., A.P.M. Lira-Gouvêa et al. 181 (UB).

Foi registrada em cerrado sentido restrito. Coletada em floração em outubro. Ocorre nas regiões Centro-Oeste, Norte e Sudeste (BFG 2018), geralmente associada aos cerrados e campos rupestres onde as queimadas são frequentes, florescendo logo após o fogo (Burman 1985).

Paspalum thrasyoides pode ser reconhecida por sua ráquis alada, ciliada, com tricomas tuberculados dourados.

\section{Agradecimentos}

Agradecemos à "Fundação de Apoio à Pesquisa do Distrito Federal" (FAPDF, Proc. 0193.000.979/2015), ao IBRAM por apoiar este trabalho, reconhecendo a importância da pesquisa científica nas áreas protegidas sob sua gestão e do aperfeiçoamento técnico de seus servidores. J.F.M. Valls também agradece ao CNPq a Bolsa de Produtividade em Pesquisa (Proc. 312215/2013-4).

\section{Referências}

Barreto IL (1956) Las especies afines a Paspalum plicatulum en Rio Grande del Sur (Brasil). Revista Argentina de Agronomia 23: 53-70.

BFG - Brazil Flora Group (2018) Brazilian Flora 2020: Innovation and collaboration to meet Target 1 of the Global Strategy for Plant Conservation (GSPC) Rodriguésia 69: 1513-1527.

Bonasora, MG, Pozzobon MT, Honfi AI \& Rua, GH (2015) Paspalum schesslii (Poaceae, Paspaleae), a new species from Mato Grosso (Brazil) with an unusual base chromosome number. Plant Systematics and Evolution 301: 2325-2339.

Burman AG (1985) The genus Thrasya HBK (Gramineae). Acta Botánica Venezuelica 14: 7-93.

Canto-Dorow TS, Longhi-Wagner HM \& Valls JFM (1996) Revisão taxonômica das espécies de Paspalum, grupo Notata (Poaceae-Paniceae) do Rio Grande do Sul, Brasil. Iheringia 47: 3-44.

Chacon RG, Martins RC, Azevedo INC, Oliveira MS \& Paiva VF (2009) Florística da Estação Ecológica do Jardim Botânico de Brasília e Jardim Botânico de Brasília. Heringeriana 3: 11-78. 
Delfini C, Souza VC \& Zuloaga FO (2017) Taxonomic revision and nomenclatural update of Paspalum sect. Pectinata (Poaceae, Panicoideae, Paspaleae). Phytotaxa 323: 1-26.

Denham SS \& Aliscioni SS (2003) A reappraisal of Paspalum pilosum and $P$ peregrinum (Poaceae: Panicoideae: Paniceae). Rhodora 105: 240-249.

Denham SS (2005) Revisión sistemática del subgénero Harpostachys de Paspalum (Poaceae: Panicoideae: Paniceae). Annals of the Missouri Botanical Garden 92: 463-532.

Denham SS, Zuloaga FO \& Morrone O (2002) Systematic revision and phylogeny of Paspalum subgenus Ceresia (Poaceae: Panicoideae: Paniceae). Annals of the Missouri Botanical Garden 89: 337 399.

Distrito Federal (2010) Sistema Distrital de Unidades de Conservação da Natureza - SDUC, Lei Complementar $n^{\circ} 827$, de 22 de julho de 2010.

Felfili JM, Silva Junior MC, Mendonça RC, Fagg CW, Filgueiras T \& Mecenas V (2007) Composição florística da estação ecológica de Águas Emendadas no Distrito Federal. Heringeriana 1: 25-85.

Filgueiras TS \& Rodrigues RS (2016) Espécies Forrageiras - Poaceae. In: Vieira RF, Camillo J, Coradin L (eds.) Espécies nativas da flora brasileira de valor econômico atual ou potencial: plantas para o futuro: Região Centro-Oeste. Série Biodiversidade, 44, Cap.5 - Espécies Forrageiras Poaceae. Ministério do Meio Ambiente, Brasília. Pp. 590-689.

Judziewicz E (1990) Family 187. Poaceae (Gramineae). In: Görts-van Rijn ARA (ed.) Flora of the Guianas, ser. A, Phanerogams. Vol. 8. Koeltz Scientific Books, Königstein. Pp. 1-727.

Morrone O, Denham SS \& Zuloaga FO (2004) Revisión taxonómica del género Paspalum grupo Eriantha (Poaceae, Panicoideae, Paniceae). Annals of the Missouri Botanical Garden 91: 225-246.

Munhoz CBR \& Felfili JM (2007) Florística do estrato herbáceo-subarbustivo de um campo limpo úmido em Brasília, Brasil. Biota Neotropica 7: 205-215

Nicola MV, Salomón L, Zuloaga FO \& Morrone O (2014) Revisión de Paspalum grupo Gardneriana (Poaceae, Paspaleae). Darwiniana, nueva serie 2: 154-173.

Oliveira RC (2004) O gênero Paspalum L, grupo Plicatula (Poaceae: Paniceae), no Brasil. Tese de Doutorado. UNICAMP, Campinas. 366p.

Oliveira RC \& Valls JFM (2001) Paspalum. In: Longhi-Wagner HM, Bittrich V, Wanderley MGL \& Shepherd GJ (eds.) Poaceae. In: Wanderley MGL, Shepherd GJ \& Giulietti AM (orgs.) Flora fanerogâmica do estado de São Paulo. Fapesp \& Hucitec, São Paulo. Vol. 1, pp. 191-228.

Oliveira RC \& Valls JFM (2002) Taxonomia de Paspalum L, grupo Linearia (Gramineae-Paniceae) do Brasil. Brazilian Journal of Botany 25: 371-389.

Oliveira RC \& Valls JFM (2008) Novos sinônimos e ocorrências em Paspalum (Poaceae). Hoehnea 35: 125-131.

Oliveira RC, Valls JFM, Gomes SM, Fagg CW \& Pozzobon MT (2015) A new species of Paspalum, Notata group (Poaceae, Paspaleae), from the Cerrado biome, Brazil: description, chromosome number, and leaf blade anatomy. Phytotaxa 203: 159-168.

Oliveira RC, Reis PA, Cardoso AG, Ribeiro AR, Berto AC, Ponciano AI, Moura CO \& Valls JFM (2016) Guia de Gramíneas do Cerrado. Rede de Sementes do Cerrado, Brasília. 201p.

Ramos DM, Valls JFM, Oliveira RC \& Graciano-Ribeiro D (2011) A new awned species of Paspalum (Poaceae, Panicoideae, Paniceae) from Brazil. Novon 21: 368-372.

Reis PA, Silva ALH, Silva AS, Valls JFM, Gomes SM \& Oliveira RC (2015) Paspalum minutispiculatum (Poaceae, Panicoideae): A new annual species from Central Brazil. Systematic Botany 40: 746-754.

Reis PA (2014) Poaceae das formações florestais e do cerrado sentido restrito do Parque Nacional de Brasília-DF, Brasil. Dissertação de Mestrado. Universidade de Brasília, Brasília. 228p.

Ribeiro ML (2011) Reserva Ecológica do IBGE: biodiversidade terrestre. Vol 1. Tomo 2. Coordenação de Recursos Naturais e Estudos Ambientais, Rio de Janeiro. 270p.

Ribeiro JF \& Walter BMT (2008) As principais fitofisionomias do bioma Cerrado. In: Sano SM, Almeida SP \& Ribeiro JF (eds.) Cerrado: ecologia e flora, Embrapa Informação Tecnológica, Brasília. Pp. 151-212.

Rodrigues-da-Silva R \& Filgueiras TS (2003) Gramíneas (Poaceae) da Área de Relevante Interesse Ecológico (ARIE) "Santuário de Vida Silvestre do Riacho Fundo", Distrito Federal, Brasil. Acta Botanica Brasilica 17: 467-486.

Sánchez-Ken JG (2010) Two new species of Paspalum (Paniceae: Panicoideae: Poaceae), a preliminary checklist of the genus in Mexico, and the identity of $P$ crinitum. Revista Mexicana de Biodiversidad 81: 629-647.

Scataglini MA, Zuloaga FO, Giussani LM, Denham SS \& Morrone O (2014) Phylogeny of new world Paspalum (Poaceae, Panicoideae, Paspaleae) based on plastid and nuclear markers. Plant Systematics and Evolution 300: 1051-1070.

Sendulsky T \& Burman AG (1978) Paspalum species of the Serra do Cipó (I): a contribution to the study of the Brazilian Poaceae. Revista Brasileira de Botânica 1: 1-15.

Sendulsky T \& Burman AG (1980) Paspalum species of the Serra do Cipó (II): a contribution to the study 
of the Brazilian Poaceae. Revista Brasileira de Botânica 3: 23-35.

Thiers B [constantemente atualizado]. Index Herbariorum: A global directory of public herbaria and associated staff. New York Botanical Garden's Virtual Herbarium. Disponível em $<$ http://sweetgum.nybg. org/ih/>. Acesso em 26 julho 2017.

Walter BMT \& Cavalcanti TB (2005) Herbários e a coleta de germoplasma. In: Walter BMT \& Cavalcanti TB (orgs.) Fundamentos para a coleta de germoplasma vegetal. Embrapa Recursos Genéticos e Biotecnologia, Brasília. 778p. [Cap.6, p.217-240].

Zuloaga FO, Pensiero J \& Morrone O (2004) Systematics of Paspalum Group Notata (Poaceae-PanicoideaePaniceae). Systematic Botany Monographs 71: 1-75.

Zuloaga FO \& Morrone O (2005) Revisión de las especies de Paspalum para América del Sur Austral (Argentina, Bolívia, sur del Brasil, Chile, Paraguay y Uruguay). Monographs in Systematic Botany from the Missouri Botanical Garden 102: 1-297. 